\title{
1 Does male mate choice select for female colouration in a promiscuous primate species?
}

2 Lucie Rigaill ${ }^{1}$, Cécile Garcia ${ }^{2}$

$3 \quad{ }^{1}$ Primate Research Institute, Kyoto University, Inuyama, Japan

$4 \quad{ }^{2}$ UMR 7206, CNRS-Muséum National d'Histoire Naturelle-Université de Paris, Paris, France

6 Abstract

7 The traditional view of sex roles and sexual selection emphasises the evolution of male ornaments as a result of female mate choice and male-male competition. Female ornaments are now receiving more attention, although their roles in mating decision are still less well understood, especially considering cases in which colourful ornaments are expressed by both

11 sexes. In this study, we analysed whether female skin colouration (luminance and redness of the face and hindquarters) influenced male mate choice and sexual behaviours in relation to intra-cycle (cycle phase), inter-cycle (number of consecutive cycles, conceptive nature of the cycle), and inter-individual (age, social rank, weight, and parity) variation in a captive population of Japanese macaques (Macaca fuscata). Males did not preferentially choose darker/redder females. Moreover, males did not appear to use female skin colouration to apportion their mating efforts on the most fertile period of the menstrual cycle or during cycles that lead to conception, or to discriminate between females. To our knowledge, our study is among the few to report a lack of male choice for female colouration in a species where both sexes potentially display ornamentation. While female colouration appeared to contain 21 information about intra-cycle, inter-cycle, and inter-individual variation in fecundity, this study

22 further demonstrates that this trait may not have been sexually selected and that males mated regardless of such variation across females. This study adds to the growing research on the role and evolution of female colouration in the context of sexual signalling and mate attraction. 
Keywords: male mate choice, female ornament, colourful trait, sexual signalling, Japanese

macaques

\section{Introduction}

Mate choice is a crucial process in reproduction. Individuals have to simultaneously choose and

avoid potential mates based on the expected benefits (e.g., good genes, social support, reproductive success) and costs (e.g., disease transmission, energy costs, intra-sexual emphasised the importance of female mate choice and male competition, and, as a consequence, the function of male ornaments has been well studied across taxa (Andersson \& Simmons, 2006, 2006; Cunningham \& Birkhead, 1998; Fitzpatrick \& Servedio, 2017). Perhaps partly as a result, the role of male mate choice on the evolution of female traits has been relatively less investigated. However, males can also face costs associated with mating in the form of energetically demanding courtship displays, mate guarding, and the production of ejaculates (Balshine et al., 2002; Dewsbury, 1982; Harshman \& Zera, 2007; Lukas \& Clutton-Brock, 2014). Similarly, female competition can also arise when females vary in reproductive quality or when the number of females exceeds male mating or mate-guarding capacities such as in cases with a high ovarian cycle synchrony or with a female-biased operational sex ratio, i.e., the ratio of the number of fertile adult males to the number of potentially fertile females in a group at a given time (Amundsen, 2000; Bonduriansky, 2001; Edward \& Chapman, 2011;

47 Kvarnemo \& Ahnesjo, 1996). Thus, male mate choice or mutual mate choice can evolve in some species to balance the ratio of costs/benefits inherent in mating (Clutton-Brock, 2007; 
There is increasing evidence that males discriminate among possible mates in species with traditional and reversed-sex roles and with different mating systems (from monogamy to polygynandry). Males may choose older females that have already successfully reproduced and raised offspring (spiny-footed lizards, Acanthodactylus erythrurus: Belliure et al., 2018; chimpanzees, Pan troglodytes: Muller et al., 2006; brown widow spiders, Latrodectus geometricus: Waner et al., 2018). Males may also choose females of higher social ranks compared with lower-ranking ones. This may be particularly adaptative in species where social rank is maternally inherited: higher-ranking offspring may achieve better condition and higher survival than lower-ranking offspring (e.g., mandrills, Mandrillus sphinx: Setchell \& Wickings, 2006). Males may also choose to mate with unmated vs. mated females to reduce sperm competition and increase their reproductive success (house crickets, Acheta domesticus: Assis et al., 2017; wolf spiders, Schizocosa ocreata: Roberts \& Uetz, 2005). To mate selectively, males may thus rely on female signals and/or express preferences for female traits that correlate with reproductive quality, such as pheromones (widow spiders, Lactrodectus hesperus: Baruffaldi \& Andrade, 2015; humans, Homo sapiens: Gildersleeve et al., 2012; wolf spiders: Roberts \& Uetz, 2005), body size (long-tailed dance flies, Rhamphomyia longicauda: Funk \& Tallamy, 2000; LeBas et al., 2003; stalk-eyed flies, Diasemopsis meigenii: Harley et al., 2013; rainbow darters, Etheostoma caeruleum: Soudry et al., 2020; hermit crabs, Pagurus middendorffii: Wada et al., 2011), or vocal pitch (humans: Pisanski et al., 2018). some species, females express sex-specific colourful ornaments whose colour and/or size are attractive to males. Such colourful ornaments are likely to be sexually selected traits as they correlate with indices of fecundity, such as sexual or egg maturity, readiness to spawn, brood size, or offspring condition (two-spotted gobies, Gobiusculus flavescens: Amundsen \& 74 Forsgren, 2001; collared lizards, Crotaphytus collaris: Baird, 2004; cichlid fishes, 
Pelvicachromis taeniatus: Baldauf et al., 2011; blue crabs, Calinnectes sapidus: Baldwin \& Johnsen, 2012; spiny-footed lizards: Belliure et al., 2018; cichlid fishes, Mikrogeophagus ramizeri: LaPlante \& Delaney, 2020; pygmy halbeaks, Dermogenys collettei: Ogden et al., 2020; striped plateau lizards, Sceloporus virgatus: Weiss, 2002, 2016). Comparatively, studies on the role of non-sex-specific colourful ornaments (i.e., ornaments expressed by both sexes) have yielded a contrasting picture of the extent to which these ornaments modulate mate choice. Female colouration may indeed represent a genetically correlated response of selection for male traits with no clear adaptive value in females. Males may thus express no preference for such traits (three spined sticklebacks, Gasterosteus aculeatus: Wright et al., 2015) or preference may be merely explained by sensory exploitation rather than sexual selection (sockeye salmons, Oncorhynchus nerka: Foote et al., 2004). However, there is some evidence that males can show preferences toward non-sex-specific colourful ornaments that reflect female reproductive state (rhesus macaque, Macaca mulatta: Dubuc et al., 2009; Higham et al., 2010, 2011; agamid lizards, Ctenophorus ornatus: LeBas \& Marshall, 2000) or reproductive success (blue tits, Cyanistes caeruleus: Doutrelant et al., 2008, 2012; Mahr et al., 2012; rhesus macaques: Dubuc, Winters, et al., 2014; rock sparrows, Petroni petronia: Pilastro et al., 2003; Griggio et al., 2009, 2005; brown boobies, Sula leucogaster: Montoya et al., 2018; blue-footed boobies, Sula nebouxii: Torres \& Velando, 2005). Therefore, in these species, female colourful ornaments can have a crucial impact on the mating strategies and reproductive success of both males and females.

Here, we investigate the potential role of female colouration on male mate choice in a promiscuous primate species, the Japanese macaque (Macaca fuscata). Female mate choice has been suggested as an important process modulating mating strategies in this species (Fujita, 2010). However, this does not mean that males should not choose or discriminate among potential mates. While their parental investment is mostly restricted to gamete contribution, 
male Japanese macaques deal with high costs associated with mating. Japanese macaques are seasonal breeders and multi-mount ejaculators and thus invest a non-negligible portion of their also face physical and physiological costs associated with extended consortships and mateguarding, reduced feeding activity, and male-male aggression leading to increased vigilance, injuries, or chronic stress (e.g., in several mammal species including primates: Alberts et al.,

to focus their mating effort on mates that are fertile and of "good quality". In Japanese macaques,

110 both sexes express red skin colouration (luminance: how light/dark the skin appears, redness:

111 at least partially reflecting the colour of the blood itself) of the face and hindquarters that peaks

112 during the mating season with sex hormones (Fooden \& Aimi, 2005). Recent studies provided

113 more insight into the potential signalling function of female colouration in this species and

114 characteristics that males may be selecting for. Hindquarter colouration may signal the intra-

115 cycle probability of ovulation while concealing its exact timing and face colouration may indicate early pregnancy (Rigaill et al., 2015, 2019). Hindquarter colouration may also contain

117 information about the inter-cycle probability of conception (Rigaill et al., 2019). Lastly, there is some evidence that skin colouration may reflect inter-individual variation (e.g., social rank,

119 weight, but not parity, Rigaill et al., 2017, 2019). Pflüger and colleagues (2014) showed that 120 males increased attention toward an experimentally intense red-coloured version of an unknown

121 female face. Thus, female colouration may be a sexually selected trait involved in mate choice 122 in Japanese macaques if males appropriately use this colourful trait to inform their mating 123 decisions. Yet, to our knowledge, no study has tested this hypothesis in a non-forced-choice 124 discrimination situation. 
Our study thus aims at identifying the potential role of female Japanese macaque face and hindquarter colouration (luminance and redness) on the likelihood that a male will engage or maintain sexual interactions with a female. If female colouration acts as a fertility signal modulating mate choice, we hypothesised that males should display more sexual behaviours toward darker/redder (i.e., stronger signal) females. We further hypothesised that the

130 relationship between male response and female colouration should vary according to a) intrapre- and fertile phases vs. the post-fertile phase), b) during cycles that lead to conception (i.e., during conceptive cycles and the first cycles of a given mating season), and/or c) with older, higher ranking, heavier, and possibly multiparous females.

\section{Methods}

\section{Subjects and housing}

141 We collected data during the 2011-2012 mating season, from early November to late January,

142 from a captive population of Japanese macaques living in a 1,210 $\mathrm{m}^{2}$ outdoor enclosure at Kyoto

143 University Primate Research Institute (KUPRI, Inuyama, Japan). The group was composed of

14439 individuals consisting of 13 adult females ( $>$ five years, mean $\pm \mathrm{SD}=10.64 \pm 6.84$ years, 145 range $=5-27), 6$ sexually immature females $(2.79 \pm 0.81$ years, range $=1-4), 3$ adult males $(>$

146 six years, $10.67 \pm 3.06$ years, range $=8-14)$, 12 sexually immature males $(2.99 \pm 1.05$ years,

147 range $=1-4)$, and 5 infants less than one year old. All adult and sexually active females and

148 males in this group were included in this study. The ratio of adult males to adult females is

149 similar to other captive and wild populations from studies of sexual behaviours and mating 
150 strategies (Fooden \& Aimi, 2005; Fujita, 2010). We did not include subadult males/females to

151 avoid confounding factors due to maturational age. Females were naturally cycling, i.e., with

152 no hormonal contraceptive treatment. Female age, weight at the beginning of the mating season

153 (to the nearest $100 \mathrm{~g}$ ), and parity (total number of infants born divided by the number of years

154 post-adulthood) were provided by the Center for Human Modeling Research of KUPRI.

155 Animals were fed twice daily between 11:00 AM and 12:00 PM and between 4:00 PM and 5:00

156 PM. Water was supplied ad libitum. The Center for Human Evolution Modeling Research of

157 the Primate Research Institute reviewed and approved our research protocol in agreement with

158 the Guidelines for the Care and Use of Nonhuman Primates of the Kyoto University Primate

159 Research Institute.

160

161 Behavioral observations

162 One observer collected behavioural data using focal animal sampling distributed from 7:00 AM

163 to 5:00 PM, 7 days a week for 3 months. We used a female-centered approach because of the

164 need to assess female trait variation in order to address the question of male responses. We

165 followed each focal female 2 hours per week in 4 blocks of 30 -min continuous focal samples

166 equally distributed across days and females. During focal observations, we recorded all social

167 and sexual behaviours between males and females, along with the direction of the behaviour

168 between the focal female and any identified adult male. We recorded all occurrences of female

169 presentations, female approaches, female mounts, female vocalisations (oestrus and copulation

170 calls), male approaches, male holding behaviours, male inspections of female genitals (i.e.,

171 visual and/or tactile and/or olfactory inspections of the female genital area), and male mounts

172 (i.e., ejaculatory and non-ejaculatory). The number of observed records for each behaviour is

173 given in Table 1. Female and male social ranks were assessed by transcribing agonistic

174 interactions for which a clear win/loss outcome was identified into an agonistic interaction 
175 matrix. We then calculated the Normalized David's Score (NDS) to assess female social rank

176 positions (de Vries et al., 2006). Given that there were only three adult males in the group, male

177 ranks were assessed as alpha (winning all agonistic interactions), beta (defeating all males

178 except the alpha male), and gamma (losing all agonistic interactions) directly from the agonistic

179 interaction matrix.

180

\begin{tabular}{rc} 
& Sum \\
\hline Female behaviours & \\
Presentations & 10 \\
Approaches & 86 \\
Mounts & 86 \\
\hline Male behaviours & \\
Approaches & 153 \\
Holding behaviors & 54 \\
Genital inspections & 39 \\
Mounts & 75 \\
\hline Female vocalisations & 30
\end{tabular}

182 Table 1. Total number of female behaviours, male behaviours, and female vocalisations recorded.

\section{Female colouration}

186 One experimenter took digital images of female face and hindquarters every two days in the

187 morning between 11:00 AM and 12:00 PM. We used a Canon EOS 350D camera with an 8 megapixel CMOS censor and an EF28-135 mm f/3.5-5.6 IS USM lens. Images were

189 standardized by daily manual setting of the white balance using an X-Rite White Balance Card

190 and a Gretag X-Rite Color Checker (GretagMacbeth ColorChecker). For each female's photo,

191 we assessed colour from the whole face and hindquarter areas excluding the eyes, nose,

192 forehead, and tail. A technician who was blind to females' identity and characteristics extracted

193 reflectance spectra using Colourworker software (Chrometics Ltd. Website, available: 
194 http://www.chrometrics.com). These spectra were converted into quantal catches, i.e., the

195 stimulation of Japanese macaque photoreceptors (Rigaill et al., 2019) using equations and

196 macaque cone ratio and spectral sensitivity values given elsewhere (Higham et al., 2010;

197 Stevens et al., 2009). Based on the quantal catch data for both face and hindquarter colouration,

198 we calculated luminance (how light/dark the skin appears) and redness (variation in chromatic

199 parameters) data.

\section{Female reproductive status}

202 To determine each female's reproductive status, we collected a total of 381 faecal samples $($ mean \pm SD per female $=29.31 \pm 3.17$, range $=24-34)$ on average every 1.59 days $($ range $=0$ 4 days) to accurately assess the ovarian cycle (Hodges \& Heistermann, 2011). We collected faecal samples in their entirety immediately after voiding, with most samples collected between 8:00 AM and 12:00 PM. All samples were then stored at $-20^{\circ} \mathrm{C}$ until processing. Faecal samples previously described by Garcia et al. (2009) to assess the presumed day of ovulation and the periovulatory period (15-day period around the estimated ovulation) of each ovarian cycle. The onset of the luteal phase was determined as the sample with a faecal PdG concentration which was at least two standard deviations greater than the mean PdG concentration of the 3-4

212 preceding baseline values (Hodges \& Heistermann, 2011). We determined the 2-day window

213 for ovulation as days -2 and -3 relative to the faecal PdG rise. The fertile phase was defined as 214 a period of five days (covering a two-day window for ovulation plus three preceding days to 215 account for sperm longevity in the reproductive tract (Behboodi et al., 1991). The five-day 216 period preceding the fertile phase represented the pre-fertile phase, while the five-day period 217 following the fertile phase was defined as the post-fertile phase. We recorded a total of 24 218 ovarian cycles (mean $\pm \mathrm{SD}$ per female $=2.0 \pm 0.83$, range $=1-3$ ) and the majority of these 
cycles were non-conceptive (19/24). One female failed to cycle during the study and was thus excluded from the analysis.

\section{Data analysis}

We restricted our analyses to the pre-fertile, fertile, and post-fertile phases. We used 173 focal observations with matching female photo (i.e., focal and photo on the same observation day) for the analyses (mean $\pm \mathrm{SD}=7.53 \pm 1.21$ per female and per cycle). We built our dataset based on the 30-min focal observations and attributed one line to each focal female - male dyad per focal observation (i.e., three lines per focal female), which was the unit of analysis.

We carried out our analyses in $\mathrm{R}$ version 3.3.3. Before running the statistical analyses, we checked for correlations between our variables of interest. Female weight correlated with parity $(\mathrm{rs}=-0.50, \mathrm{P}<0.001)$ and age $(\mathrm{rs}=0.73, \mathrm{P}<0.001)$. Parity correlated with age $(\mathrm{rs}=-$

$0.42, \mathrm{P}<0.001)$. Parity also weakly correlated with female social rank ( $\mathrm{rs}=-0.25, \mathrm{P}<0.001)$.

232 We thus excluded female age and weight from our analyses. None of the female behaviours

233 (i.e., presentations, approaches, and mounts) were correlated with each other (all P > 0.05).

234 None of the male behaviours (i.e., approaches, holding behaviours, genital inspections, and 235 mounts) were correlated with each other (all $\mathrm{P}>0.05)$.

We aimed at testing whether the likelihood of a male behavioural response (binary variable: 1 = occurrence, $0=$ non-occurrence) toward a female was predicted by female colouration, i.e., whether males where more likely to engage in or maintain sexual interactions with darker/redder females. The little occurrences of copulatory event alone prevented us from 240 analysing the effect of female colouration on this behaviour only. We thus computed a binary 241 response variable that corresponded to a male behavioural response as the occurrence of at least 242 one of the behaviours involved in establishing and maintaining consortship that were displayed 243 by the interacting male of the dyad (i.e., approaches, holding behaviours, genital inspections, 
244 and copulations). Similarly, we also computed a binary variable that corresponded to a female

245 behavioural display (hereafter, female behaviours), as the occurrence of at least one of the

246 behaviours involved in establishing and maintaining consortship that were displayed by the

247 interacting female of the dyad (i.e., presentations, approaches, and mounts).

We built a series of generalized linear mixed models with a binomial error structure and

249 logit link function with the function glmer from the lme4 package (Bates et al., 2015) to

250 investigate the relationship between male behavioural response (binary response variable) and

251 female hindquarter and face luminance and redness (continuous predictor variables). Inspection

252 of the cumulative distribution functions revealed good fits to the normal distribution for 253 hindquarter luminance and to the lognormal distribution for face luminance, face redness, and

254 hindquarter redness. We first constructed three different models to test the relationship between 255 male behaviours and female face colouration (luminance and redness), male behaviours and 256 female hindquarter colouration (luminance and redness), and male behaviours and female face and hindquarter colouration (luminance and redness). To account for a) intra-cycle, b) intercycle, and c) inter-individual effects on the potential relationship between female colouration 259 and male response, our three models included interactions between female colouration and a) 260 the cycle phase (categorical variable, three levels: pre-fertile, fertile, and post-fertile phases), 261 b) the number of consecutive cycles (continuous variable) and the conceptive nature of the cycle 262 (binary variable: $1=$ conceptive, $0=$ non-conceptive cycles, hereafter conception), and c) 263 female social rank (continuous variable) and parity (continuous variable). We also included 264 female behaviours (binary variable) and male social rank (categorical variable, three levels: 265 alpha, beta, gamma) as covariates to account for the potential effects of female direct 266 solicitation and male social attributes on mating decisions. Finally, the date of the focal, female 267 identity, and male identity were included as random factors. We also constructed a null model 268 in which the predictor variables and all covariates were removed but the random effects 
structure was maintained. All continuous variables were standardized to mean $=0$ and $\mathrm{SD}=1$

prior to modelling to improve model performance and interpretability (Harrison et al., 2018).

We checked for variance inflation $\left(\operatorname{GVIF}^{(1 /(2 x D f)}<3\right)$ using the car package $($ Fox \& Weisberg, 2019); we excluded the number of consecutive cycles from the models due to variance inflation.

We ensured that all relevant model assumptions (homogeneity of the residuals and stability of estimates) were met by visually inspecting histograms of the residuals and plots of residuals against fitted values.

We used an information-theory approach to objectively compare and rank the four candidate models (i.e., null model, face colouration model, hindquarter colouration model, and face and hindquarter colouration model) in terms of how well they fitted the existing data. This method allowed us to assess the likelihood that one or more models among the candidates is/are best supported by the data (Burnham et al., 2011; Symonds \& Moussalli, 2011). We used the function model.sel of the MuMIn package (Barton, 2020) to rank models based on their respective Akaike's information criterion corrected for small sample size (AICc values). We considered models with $\triangle \mathrm{AICc}$ (the difference in AICc values between the smallest AICc and

284 the other AICc values) below four as competitive models with the plausibly best model in the 285 set of candidate models (Burnham \& Anderson, 2002). We reported the weight of the models 286 which indicates to what extent one candidate model is more likely than another to provide a 287 reasonable explanation of the variance in the data, along with the evidence ratio (ER) which 288 indicates the extent to which the higher-ranked model is more parsimonious than another 289 candidate model. We also reported the marginal (fixed effects alone) and conditional (fixed 290 effects and random structures) coefficients of determination $\left(\mathrm{R}^{2} \mathrm{~m}\right.$ and $\left.\mathrm{R}^{2} \mathrm{c}\right)$ of all models using 291 the function r.squaredGLMM (Nakagawa \& Schielzeth, 2013). We extracted weighted 292 parameter estimates $(\beta)$, standard errors (SE), and 95\% confidence intervals (95\% CIs) of model 
intercepts and predictors from conditional averaging of the 4 candidate models (function model.avg).

\section{Results}

Among the candidate models, the model including female hindquarter colouration (luminance and redness) and covariates had the highest weight (0.998) and more than 499 times more empirical support than the competing models (face colouration: $\triangle \mathrm{AICc}=12.3$; face and random effects explained around $28 \%$ of the observed variance in the occurrence of male behavioural responses. interaction between male behavioural responses and female colouration (luminance and redness of the face and hindquarters, all $\mathrm{P}>0.50$, Table 3, Figure 1A). There was a slight tendency for non-conceptive vs. conceptive cycles $(\beta=-0.96 \pm 0.52 \mathrm{SE}, \mathrm{P}=0.068,95 \% \mathrm{CI}=-1.98 ; 0.07$,

Table 3, Figure 1B). In other words, our results suggest that during conceptive cycles, there was a higher probability of male behavioural responses when the signal was strong (lower luminance $=$ darker hindquarters). However, female face and hindquarter colouration per se did not explain variation in the occurrence of male behavioural responses (luminance and redness,

312 all $\mathrm{P}>0.05$, Table 3). Similarly, the likelihood of observing male sexual behaviours was not 313 influenced by cycle phase or the conceptive nature of the cycle (all $\mathrm{P}>0.50$, Table 3 ).

314 Males were more likely to display sexual behaviours toward females that have solicited 315 or interacted with them $(\beta=2.99 \pm 0.42 \mathrm{SE}, \mathrm{P}<0.001,95 \% \mathrm{CI}=2.15 ; 3.82$, Table 3$)$. Males 316 were also more likely to display sexual behaviours toward females of lower parity $(ß=-1.17 \pm$ $3170.53 \mathrm{SE}, \mathrm{P}=0.026,95 \% \mathrm{CI}=-2.20 ;-0.14$, Table 3$)$ and of higher social rank $(\beta=0.60 \pm 0.28$ 
$318 \mathrm{SE}, \mathrm{P}=0.031,95 \% \mathrm{CI}=0.05,0.15$, Table 3 ). Male social rank was positively related to the

319 occurrence of male sexual behaviours (alpha vs. beta: $\beta=-0.97 \pm 0.37 \mathrm{SE}, \mathrm{P}=0.010,95 \% \mathrm{CI}$

$320=-1.71 ;-0.24$, alpha vs. gamma: $\beta=-1.45 \pm 0.41 \mathrm{SE}, \mathrm{P}<0.001,95 \% \mathrm{CI}=-2.26 ;-0.65$, Table

$3213)$.

\begin{tabular}{lccccccc} 
Models & $\mathbf{k}$ & $\mathbf{l o g L i k}$ & $\mathbf{A I C c}$ & $\Delta$ AICc & weight & $\mathbf{E R}$ & $\mathbf{R}^{2} \mathbf{m}-\mathbf{R}^{2} \mathbf{c}$ \\
\hline Hindquarter colouration & 24 & -140.1 & 330.6 & 0.0 & 0.998 & - & $0.26-0.28$ \\
$\begin{array}{l}\text { Face colouration } \\
\begin{array}{l}\text { Face and hindquarter } \\
\text { colouration }\end{array}\end{array}$ & 24 & -146.2 & 342.9 & 12.31 & 0.002 & 499 & $0.19-0.23$ \\
Null & 36 & -135.3 & 348.2 & 17.59 & 0.00 & - & $0.29-0.31$ \\
& 4 & -186.2 & 380.4 & 49.84 & 0.00 & - & $0.00-0.14$
\end{tabular}

323

324 Table 2. Characteristics of candidate models. $k$ : number of predictors, AICc: corrected Akaike's

325 information criterion, $\triangle A I C c$ : AICc difference between higher-ranked models and other 326 candidate models., weight: model probabilities, ER: evidence ratios, $R^{2} m-R^{2} c$ : marginal and 327 conditional coefficients of determination. Candidate models are presented from higher-ranked 328 to lower-ranked ones.

\begin{tabular}{rccccc} 
& $\beta$ & $\mathrm{SE}$ & z-value & $\mathrm{P}$ & 95\% CI \\
\hline Intercept & $\mathbf{- 1 . 2 0}$ & $\mathbf{0 . 5 3}$ & $\mathbf{2 . 2 5}$ & $\mathbf{0 . 0 2 4}$ & $\mathbf{- 2 . 4 5} ; \mathbf{- 0 . 1 6}$ \\
Face luminance & 0.21 & 0.44 & 0.47 & 0.64 & $-0.66 ; 1.08$ \\
Face redness & 0.39 & 0.60 & 0.64 & 0.52 & $-0.79 ; 1.57$ \\
Hindquarter luminance & 0.50 & 0.37 & 1.36 & 0.17 & $-0.22 ; 1.23$ \\
Hindquarter redness & -0.45 & 0.38 & 1.16 & 0.25 & $-1.20 ; 0.31$ \\
Female behaviour & $\mathbf{2 . 9 9}$ & $\mathbf{0 . 4 2}$ & $\mathbf{7 . 0 2}$ & $<\mathbf{0 . 0 0 1}$ & $\mathbf{2 . 1 5} ; \mathbf{3 . 8 2}$ \\
Cycle phase (fertile vs. prefertile) & -0.09 & 0.42 & 0.21 & 0.84 & $-0.90 ; 0.73$ \\
Cycle phase (fertile vs. post-fertile) & -0.25 & 0.40 & 0.63 & 0.53 & $-1.03 ; 0.53$ \\
Conception & -0.25 & 0.56 & 0.44 & 0.66 & $-1.35 ; 0.86$ \\
Parity & $\mathbf{- 1 . 1 7}$ & $\mathbf{0 . 5 3}$ & $\mathbf{2 . 2 2}$ & $\mathbf{0 . 0 2 6}$ & $\mathbf{- 2 . 2 0 ; - 0 . 1 4}$ \\
Female rank & $\mathbf{0 . 6 0}$ & $\mathbf{0 . 2 8}$ & $\mathbf{2 . 1 5}$ & $\mathbf{0 . 0 3 1}$ & $\mathbf{0 . 0 5} ; \mathbf{1 . 1 5}$ \\
Male rank (alpha vs. beta) & $\mathbf{- 0 . 9 7}$ & $\mathbf{0 . 3 7}$ & $\mathbf{2 . 6 0}$ & $\mathbf{0 . 0 0 9}$ & $\mathbf{- 1 . 7 1 ; - 0 . 2 4}$ \\
Male rank (alpha vs. gamma) & $\mathbf{- 1 . 4 5}$ & $\mathbf{0 . 4 1}$ & $\mathbf{3 . 5 4}$ & $\mathbf{< 0 . 0 0 1}$ & $\mathbf{- 2 . 2 6 ; - 0 . 6 5}$ \\
\hline
\end{tabular}

Interaction: face luminance $\mathrm{x}$ 


\begin{tabular}{rrrrrr} 
Cycle phase (fertile vs. prefertile) & -0.43 & 0.47 & 0.91 & 0.36 & $-1.34 ; 0.49$ \\
Cycle phase (fertile vs. post-fertile) & -0.25 & 0.47 & 0.52 & 0.60 & $-1.18 ; 0.68$ \\
Conception & -0.50 & 0.47 & 1.07 & 0.28 & $-1.42 ; 0.42$ \\
Parity & 0.25 & 0.41 & 0.62 & 0.53 & $-0.55 ; 1.06$ \\
Female rank & 0.14 & 0.22 & 0.66 & 0.51 & $-0.28 ; 0.57$ \\
\hline Interaction: face redness x & & & & & \\
Cycle phase (fertile vs. prefertile) & 0.22 & 0.54 & 0.41 & 0.68 & $-0.84 ; 1.29$ \\
Cycle phase (fertile vs. post-fertile) & -0.01 & 0.52 & 0.03 & 0.97 & $-1.04 ; 1.00$ \\
Conception & -0.40 & -0.49 & 0.82 & 0.41 & $-1.36 ; 0.55$ \\
Parity & -0.05 & 0.43 & 0.13 & 0.90 & $-0.89,0.78$ \\
Female rank & 0.28 & 0.21 & 1.33 & 0.18 & $-0.13 ; 0.70$ \\
\hline Interaction: hindquarter luminance x & & & & & \\
Cycle phase (fertile vs. prefertile) & 0.33 & 0.46 & 0.72 & 0.47 & $-0.57 ; 1.22$ \\
Cycle phase (fertile vs. post-fertile) & -0.65 & 0.40 & 1.61 & 0.11 & $-1.44 ; 0.14$ \\
Conception & -0.96 & 0.52 & 1.82 & 0.068 & $-1.98 ; 0.07$ \\
Parity & 0.00 & 0.37 & 0.00 & 1.00 & $-0.73 ; 0.73$ \\
Female rank & 0.07 & 0.20 & 0.33 & 0.74 & $-0.32 ; 0.45$ \\
\hline Interaction: hindquarter redness x & & & & & \\
Cycle phase (fertile vs. prefertile) & -0.53 & 0.51 & 1.04 & 0.30 & $-1.53 ; 0.47$ \\
Cycle phase (fertile vs. post-fertile) & -0.45 & 0.44 & 1.02 & 0.31 & $-1.31 ; 0.41$ \\
Conception & 0.56 & 0.64 & 0.88 & 0.38 & $-0.70 ; 1.83$ \\
Parity & 0.05 & 0.40 & 0.12 & 0.91 & $-0.73 ; 0.83$ \\
Female rank & 0.36 & 0.22 & 1.66 & 0.10 & $-0.07 ; 0.78$ \\
\hline & & & & &
\end{tabular}

Table 3. Model averaged parameters estimates $(\beta) \pm$ adjusted standard errors (SE), z-value,

332 probability $(\mathrm{P})$, and confidence intervals (95\% CIs) from conditional averaging of all candidate

333 models. For each categorical comparison, the first level indicate baseline. Results for which CI

334 does not include zero are presented in bold, trends are presented in italic. 

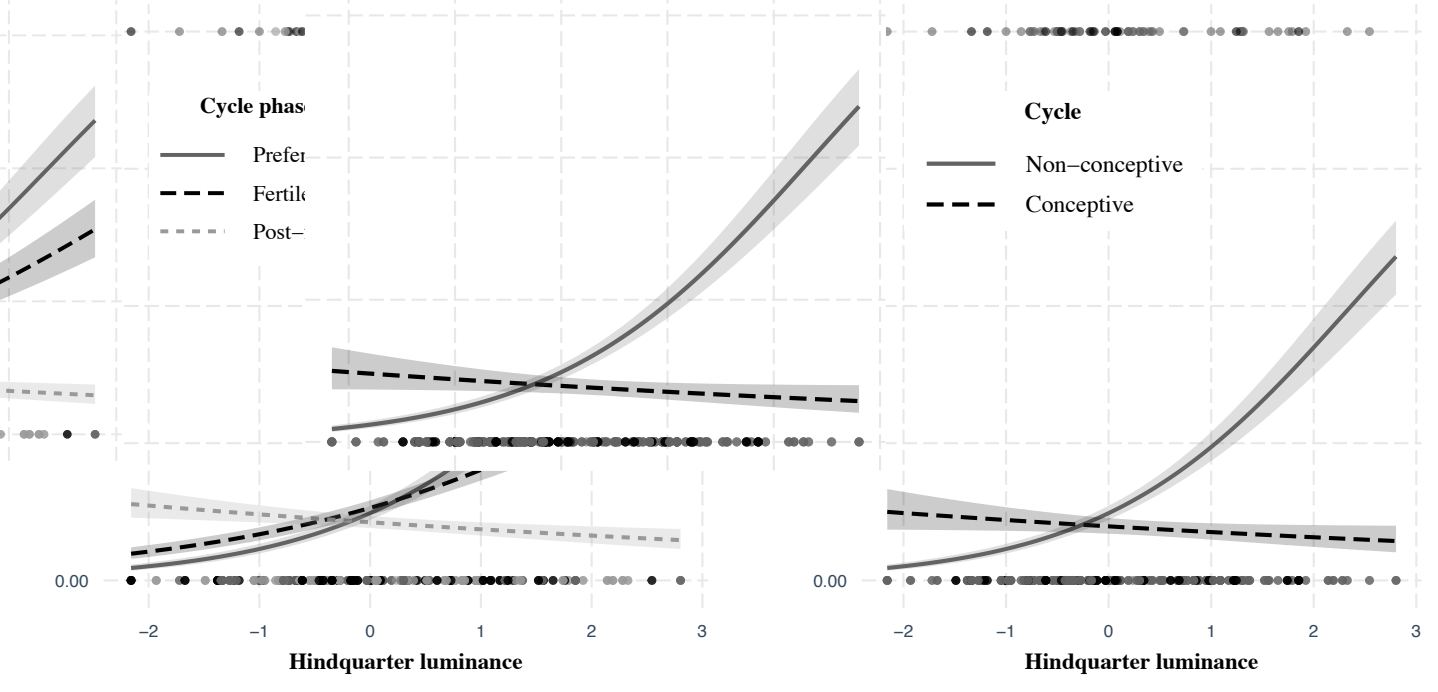

337 Figure 1. Interaction plot of the generalized linear mixed model exploring the relationship 338 between male behavioural response, female hindquarter luminance (log) across cycle phases 339 (A) and between conceptive vs. non-conceptive cycles (B).

\section{Discussion}

342 We examined male choice toward a non-sex-specific colourful ornament in a promiscuous

343 primate species with traditional sex roles and demonstrated that males did not bias their sexual

344 behaviours toward darker/redder females. Our results also showed that male Japanese macaques

345 did not seem to use female colouration (luminance and redness of the face and hindquarters) to

346 focus their mating effort on the most fertile period of the menstrual cycle, or during cycles that

347 lead to conception, or on "good quality" mates.

The lack of effect of female colouration on male sexual behaviours -or in other words,

349 the lack of male choice for darker/redder females- is surprising given that previous studies

350 suggested a potential role of female colouration on male mate choice in Japanese macaques

351 (face redness: Pflüger et al., 2014; face and hindquarter luminance and redness: Rigaill et al., 352 2019). While we investigated changes in male sexual behaviours toward group-member

353 females varying in skin colouration and characteristics, Pflüger et al. (2014) investigated male 354 responses toward two visual stimuli of an unknown female face. A red effect may have been 
over-estimated due to the binary choice, the lack of familiarity with the stimuli which significantly matters in communication (e.g., visual trait: Higham et al., 2011; odorant trait: Setchell et al., 2010; auditory trait: Townsend et al., 2011), or the lack of precise measure of attention such as tracking fine-scale eye movements (Hopper et al., 2020; Yorzinski et al., 2013).

Our present study demonstrated that female colouration is unlikely to be a sexual signal since males did not appear to use this trait to discriminate when and with whom to mate to reproduce efficiently. Skin colouration may thus correlate with female characteristics without having a signalling function (correlation without causation). This highlights the importance of studying (what information may be contained) and perceiver (how the trait may affect behaviours) perspectives. Alternatively, we cannot completely rule out that mate choice for female colouration occurs in this species but that our data did not capture such effect. One may argue that males of this group may not rely - or need to rely - on this colouration to make their mating a role in male sexual strategies in this species where females vary in quality and female-female competition is high, one may have expected the alpha male to express mate choice as he has

372 priority of access to mating. However, the alpha male did not appear to do so (see 373 supplementary material).

In the absence of male mate choice for a female trait and of a clear ovulatory signalling 375 in this species (Garcia et al., 2009; O’Neill et al., 2004; Rigaill et al., 2019), does this mean that 376 males mate randomly? This is highly unlikely considering the energetic costs of extended sperm 377 production, prolonged consortship, and male-male competition (Matsubara, 2003; Thomsen et 378 al., 2006). While female colouration may not inform males about the probability of ovulation 379 or female characteristics, this traits appears to be involved in the communication of pregnancy 
status (information content: Rigaill et al., 2015). Moreover, males have been found to reduce or avoid mating with pregnant females in populations facing higher energetic constrains (Fujita, present study that males were more likely to respond to female solicitations that could be used to apportion their mating effort toward receptive females vs. non-cycling females. Males may thus adapt their mating strategies according to female behaviour and to their access to mate by either intensifying mate guarding (higher-ranking males) or seizing a mating opportunity (lower-ranking males). Monitoring female behaviours would ultimately benefit to both higherand lower-ranking males by balancing the costs and benefits of mate searching, direct competition, and mating. Alternatively, male sexual behaviours may be a by-product response of female mate choice which has been reported as an active reproductive strategy in Japanese macaques (Huffman, 1991, 1992; Soltis et al., 1997). We also found that males may bias their mate choice toward females at the beginning of their reproductive history and toward higherranking females. This may be related to parental investment as lower-ranking females and/or those toward the end of their reproductive history may have less energy to invest in future offspring or be less capable to balance the costs of reproduction with other costs (e.g., competition, health) than higher-ranking females and/or those at the beginning of their reproductive history (e.g., mandrills, Setchell \& Wickings, 2006). More precise data on the interaction between female behaviours and characteristics and male mate choice is needed to 400 better understand the process of male mate choice in Japanese macaques. Studies of the role of non-sex-specific colourful ornaments displayed on feather or skin have been relatively limited in comparison with sex-specific colourful ornaments in both males and females. From this rather incomplete picture, it appears that male choice and preferences 404 for female traits may evolve because of the costs associated with reproduction. One factor may 
be the cost of sexual signalling itself, when female ornamentations are costly to produce or maintain and thus impact the energy allocated to reproduction and ultimately, offspring quality and survival (Doutrelant et al., 2008, 2012; Griggio et al., 2009; Peters et al., 2011; Pilastro et al., 2003), although it is complicated to accurately assess such signalling costs. Another factor may be the shared costs of rearing offspring in socially monogamous species displaying extra410 pair copulations (Griggio et al., 2005; Mahr et al., 2012; Torres \& Velando, 2005). Under such conditions, both males and females would benefit from traits indicative of one's fecundity to

412 adjust their mating and parental effort according to the costs and prospective benefits of 413 signalling to and of reproducing with a particular mate. Alternatively, male choice for a 414 colourful trait has been also described in at least one promiscuous species with traditional sex 415 roles. In the territorial agamid lizards, female colourful traits appear to convey information about receptivity: male choice may thus also evolve to maximize reproductive success when mating decisions are limited or constrained (LeBas \& Marshall, 2000). colouration (sockeye salmons: Foote et al., 2004; threespine sticklebacks: Wright et al., 2015). A possible explanation could involve the operational sex ratio. A female-biased operational sex ratio, i.e., when males are a limited resource, could favour female-female competition and ornamentation. However, in seasonal breeders, it is likely that the number of cycling, receptive, and defendable females within a group or location decreases rapidly during the mating season 424 as a consequence of reproductive synchrony (Ims, 1990; Thompson, 2018). Male-male 425 competition for the access to mates may thus strengthen which would select for male ornaments, 426 especially in species where the cost of reproduction is heavier on females than males. Such 427 scenario may explain the lack of male choice for female colouration in Japanese macaques. 428 Females are indeed more likely to conceive at the beginning of the mating season and to invest 
availability and thermoregulation (Fujita, 2010; Garcia et al., 2010, 2011). Thus, female colouration may only represent a correlated response of selection for ornamentation in males

432 (Lande, 1980). The signalling function of male colouration and its role on mate choice in Japanese macaques is still unknown. However, evidence from other primate species suggests that male colouration can correlate with some aspects of male-male competition (geladas, Theropithecus gelada: Bergman et al., 2009; snub-nosed monkeys, Rhinopithecus bieti: Grueter et al., 2015; drills, Mandrillus leucophaeus: Marty et al., 2009; rhesus macaques: Petersdorf et al., 2017; mandrills: Setchell \& Dixson, 2001) and may be used in female mate choice (rhesus macaques: Dubuc, Allen, et al., 2014; Dubuc et al., 2016; Waitt et al., 2003).

In conclusion, we found no clear evidence that female colouration (luminance and 440 redness of the face and hindquarters) influence male mate choice in Japanese macaques. Female colouration does not appear to be a sexually selected trait conveying relevant information about intra-cycle, inter-cycle, and inter-individual differences in fecundity. However, future studies should investigate the potential role of both female and male colouration in the communication of reproductive status (e.g., cycling vs. non cycling, pregnancy), male-male competition, and

445 female mate choice to draft any definite conclusions. Whether reproductive seasonality and 446 reproductive costs influence the evolution of male mate choice and female traits remains an 447 open question, especially in primates for which little data is available. Further studies focusing 448 on the relationship between female/male colouration and male/female sexual behaviours and 449 mate choice in species facing different reproductive constraint should help to improve our 450 understanding of the role and evolution of non-sex-specific colourful ornaments in primates.

\section{Acknowledgments}

453 The authors thank The Center for Human Evolution Modeling Research of the Primate 454 Research Institute and M.A. Huffman for use of the primate facilities. We thank A. Chimènes 
bioRxiv preprint doi: https://doi.org/10.1101/2020.12.08.415810; this version posted December 9,2020 . The copyright holder for this preprint (which was not certified by peer review) is the author/funder, who has granted bioRxiv a license to display the preprint in perpetuity. It is made available under aCC-BY-NC-ND 4.0 International license.

for her help with the preparation of the digital photography. We also thank J. Duboscq and AJJ.

MacIntosh for helpful discussion on the analyses and comments on an earlier version of this

manuscript. This work was financially supported by the Centre National de la Recherche Scientifique (France) to CG.

\section{References}

Alberts, S. C., Altmann, J., \& Wilson, M. L. (1996). Mate guarding constrains foraging activity of male baboons. Animal Behaviour, 51(6), 1269-1277. https://doi.org/10.1006/anbe.1996.0131 Amundsen, T. (2000). Why are female birds ornamented? Trends in Ecology \& Evolution, 15(4), 149-155. https://doi.org/10.1016/S0169-5347(99)01800-5 Amundsen, T., \& Forsgren, E. (2001). Male mate choice selects for female coloration in a fish. Proceedings of the National Academy of Sciences, 98(23), 13155-13160. https://doi.org/10.1073/pnas.211439298

Andersson, M., \& Simmons, L. W. (2006). Sexual selection and mate choice. Trends in Ecology \& Evolution, 21(6), 296-302. https://doi.org/10.1016/j.tree.2006.03.015 Assis, B. A., Trietsch, C., \& Foellmer, M. W. (2017). Male mate choice based on chemical cues in the cricket Acheta domesticus (Orthoptera: Gryllidae). Ecological Entomology, 42(1), 11-17. https://doi.org/10.1111/een.12353

Baird, T. A. (2004). Reproductive coloration in female collared lizards, crotophytus collaris, stimulates courtship by males. Herpetologica, 60(3), 337-348. https://doi.org/10.1655/03-17 Baldauf, S. A., Bakker, T. C. M., Kullmann, H., \& Thünken, T. (2011). Female nuptial coloration and its adaptive significance in a mutual mate choice system. Behavioral Ecology, 22(3), 478-485. https://doi.org/10.1093/beheco/arq226

Baldwin, J., \& Johnsen, S. (2012). The male blue crab, Callinectes sapidus, uses both chromatic and achromatic cues during mate choice. Journal of Experimental Biology. https://doi.org/10.1242/jeb.067512

Balshine, S., Kempenaers, B., Székely, T., Kokko, H., \& Johnstone, R. A. (2002). Why is mutual mate choice not the norm? Operational sex ratios, sex roles and the evolution of sexually dimorphic and monomorphic signalling. Philosophical Transactions of the Royal Society of London. Series B: Biological Sciences, 357(1419), 319-330.

https://doi.org/10.1098/rstb.2001.0926

Bartoń, K. (2020). MuMIn: Multi-Model Inference. R package version 1.43.17. https://CRAN.R-project.org/package=MuMIn

Baruffaldi, L., \& Andrade, M. C. B. (2015). Contact pheromones mediate male preference in black widow spiders: Avoidance of hungry sexual cannibals? Animal Behaviour, 102, 25-32. https://doi.org/10.1016/j.anbehav.2015.01.007

Bates, D., Mächler, M., Bolker, B., \& Walker, S. (2015). Fitting linear mixed-effects models using lme4. Journal of Statistical Software, 67(1). https://doi.org/10.18637/jss.v067.i01 Behboodi, E., Katz, D., Samuels, S., Tell, L., Hendrickx, A., \& Lasley, B. (1991). The use of a urinary estrone conjugates assay for detection of optimal mating time in the cynomolgus macaque (Macaca fascicularis). Journal of Medical Primatology, 20(5), 229-234. Belliure, J., Fresnillo, B., \& Cuervo, J. J. (2018). Male mate choice based on female coloration in a lizard: The role of a juvenile trait. Behavioral Ecology, 29(3), 543-552. 
https://doi.org/10.1093/beheco/ary005

Beltran-Bech, S., \& Richard, F.-J. (2014). Impact of infection on mate choice. Animal Behaviour, 90, 159-170. https://doi.org/10.1016/j.anbehav.2014.01.026

Bergman, T. J., Ho, L., \& Beehner, J. C. (2009). Chest color and social status in male geladas (Theropithecus gelada). International Journal of Primatology, 30(6), 791-806. https://doi.org/10.1007/s10764-009-9374-x

Bonduriansky, R. (2001). The evolution of male mate choice in insects: A synthesis of ideas and evidence. Biological Reviews, 76(3), 305-339. https://doi.org/10.1017/S1464793101005693 Burnham, K. P., \& Anderson, D. R. (2002). Model Selection and Multimodel Inference: A Practical Information-Theoretic Approach (2nd ed.). Springer-Verlag.

Burnham, K. P., Anderson, D. R., \& Huyvaert, K. P. (2011). AIC model selection and multimodel inference in behavioral ecology: Some background, observations, and comparisons. Behavioral Ecology and Sociobiology, 65(1), 23-35. https://doi.org/10.1007/s00265-010-1029-6 Clutton-Brock, T. (2007). Sexual selection in males and females. Science, 318(5858), 18821885. https://doi.org/10.1126/science.1133311 Cunningham, E., \& Birkhead, T. (1998). Sex roles and sexual selection. Animal Behaviour, 56(6), 1311-1321. https://doi.org/10.1006/anbe.1998.0953

de Vries, H., Stevens, J. M. G., \& Vervaecke, H. (2006). Measuring and testing the steepness of dominance hierarchies. Animal Behaviour, 71(3), 585-592.

https://doi.org/10.1016/j.anbehav.2005.05.015 Dewsbury, D. A. (1982). Ejaculate cost and male choice. The American Naturalist, 119(5), 601-610.

Doutrelant, C., Grégoire, A., Grnac, N., Gomez, D., Lambrechts, M., \& Perret, P. (2008). Female coloration indicates female reproductive capacity in blue tits. Journal of Evolutionary Biology, 21(1), 226-233. https://doi.org/10.1111/j.1420-9101.2007.01451.x

Doutrelant, C., Grégoire, A., Midamegbe, A., Lambrechts, M., \& Perret, P. (2012). Female plumage coloration is sensitive to the cost of reproduction. An experiment in blue tits. Journal of Animal Ecology, 81(1), 87-96. https://doi.org/10.1111/j.1365-2656.2011.01889.x Dubuc, C., Allen, W. L., Cascio, J., Lee, D. S., Maestripieri, D., Petersdorf, M., Winters, S., \& Higham, J. P. (2016). Who cares? Experimental attention biases provide new insights into a mammalian sexual signal. Behavioral Ecology, 27(1), 68-74.

https://doi.org/10.1093/beheco/arv117 Dubuc, C., Allen, W. L., Maestripieri, D., \& Higham, J. P. (2014). Is male rhesus macaque red color ornamentation attractive to females? Behavioral Ecology and Sociobiology, 68, 1215-1224.

Dubuc, C., Brent, L. J. N., Accamando, A. K., Gerald, M. S., MacLarnon, A., Semple, S., Heistermann, M., \& Engelhardt, A. (2009). Sexual skin color contains information about the timing of the fertile phase in free-ranging Macaca mulatta. International Journal of Primatology, 30(6), 777-789. https://doi.org/10.1007/s10764-009-9369-7

Dubuc, C., Winters, S., Allen, W. L., Brent, L. J. N., Cascio, J., Maestripieri, D., RuizLambides, A. V., Widdig, A., \& Higham, J. P. (2014). Sexually selected skin colour is heritable and related to fecundity in a non-human primate. Proceedings of the Royal Society of London B: Biological Sciences, 281(1794), 20141602. https://doi.org/10.1098/rspb.2014.1602

Edward, D. A., \& Chapman, T. (2011). The evolution and significance of male mate choice. Trends in Ecology \& Evolution, 26(12), 647-654. https://doi.org/10.1016/j.tree.2011.07.012 Fitzpatrick, C. L., \& Servedio, M. R. (2017). Male mate choice, male quality, and the potential for sexual selection on female traits under polygyny. Evolution, 71(1), 174-183. 
Fitzpatrick, C. L., \& Servedio, M. R. (2018). The evolution of male mate choice and female ornamentation: A review of mathematical models. Current Zoology, 64(3), 323-333. https://doi.org/10.1093/cz/zoy029 Fooden, J., \& Aimi, M. (2005). Systematic review of Japanese macaques, Macaca fuscata (Gray, 1870). Fieldiana Zoology, 104, 1-198. sockeye salmon: Implications for the phenotypic convergence of anadromous and nonanadromous morphs. Animal Behaviour, 67(1), 69-83. https://doi.org/10.1016/j.anbehav.2003.02.004 Fox, J., \& Weisberg, S. (2019). An $\{\mathrm{R}\}$ Companion to Applied Regression, Third Edition. Thousand Oaks CA: Sage. https://socialsciences.mcmaster.ca/jfox/Books/Companion/ Fujita, S. (2010). Interaction between male and female mating strategies and factors affecting reproductive outcome. In N. Nakagawa, M. Nakamichi, \& H. Sugiura (Eds.), The Japanese macaques (pp. 221-239). Springer Japan.

Funk, null, \& Tallamy, null. (2000). Courtship role reversal and deceptive signals in the long-tailed dance fly, Rhamphomyia longicauda. Animal Behaviour, 59(2), 411-421. https://doi.org/10.1006/anbe.1999.1310

Garcia, C., Huffman, M. A., Shimizu, K., \& Speakman, J. R. (2011). Energetic consequences of seasonal breeding in female Japanese macaques (Macaca fuscata). American Journal of Physical Anthropology, 146(2), 161-170. https://doi.org/10.1002/ajpa.21553

Garcia, C., Huffman, M., \& Shimizu, K. (2010). Seasonal and reproductive variation in body condition in captive female Japanese macaques (Macaca fuscata). American Journal of Primatology, 72(4), 277-286. https://doi.org/10.1002/ajp.20777

Garcia, C., Shimizu, K., \& Huffman, M. (2009). Relationship between sexual interactions and the timing of the fertile phase in captive female Japanese macaques (Macaca fuscata). American Journal of Primatology, 71(10), 868-879. https://doi.org/10.1002/ajp.20717 Gildersleeve, K. A., Haselton, M. G., Larson, C. M., \& Pillsworth, E. G. (2012). Body odor attractiveness as a cue of impending ovulation in women: Evidence from a study using hormone-confirmed ovulation. Hormones and Behavior, 61(2), 157-166. https://doi.org/10.1016/j.yhbeh.2011.11.005

Girard-Buttoz, C., Heistermann, M., Rahmi, E., Marzec, A., Agil, M., Fauzan, P. A., \& Engelhardt, A. (2014). Mate-guarding constrains feeding activity but not energetic status of wild male long-tailed macaques (Macaca fascicularis). Behavioral Ecology and Sociobiology, 68(4), 583-595. https://doi.org/10.1007/s00265-013-1673-8

Griggio, M., Devigili, A., Hoi, H., \& Pilastro, A. (2009). Female ornamentation and directional male mate preference in the rock sparrow. Behavioral Ecology, 20(5), 1072-1078. https://doi.org/10.1093/beheco/arp099

Griggio, M., Valera, F., Casas, A., \& Pilastro, A. (2005). Males prefer ornamented females: A field experiment of male choice in the rock sparrow. Animal Behaviour, 69(6), 1243-1250. https://doi.org/10.1016/j.anbehav.2004.10.004

590 Grueter, C. C., Zhu, P., Allen, W. L., Higham, J. P., Ren, B., \& Li, M. (2015). Sexually selected lip colour indicates male group-holding status in the mating season in a multi-level primate society. Royal Society Open Science, 2(12), 150490. https://doi.org/10.1098/rsos.150490 Harley, E., Birge, L. M., Small, J., Tazzyman, S. J., Pomiankowski, A., \& Fowler, K. (2013). Ejaculate investment and attractiveness in the stalk-eyed fly, Diasemopsis meigenii. Ecology and Evolution, 3(6), 1529-1538. https://doi.org/10.1002/ece3.544

Harrison, X. A., Donaldson, L., Correa-Cano, M. E., Evans, J., Fisher, D. N., Goodwin, C. E. D., Robinson, B. S., Hodgson, D. J., \& Inger, R. (2018). A brief introduction to mixed effects 
modelling and multi-model inference in ecology. PeerJ, 6, e4794. https://doi.org/10.7717/peerj.4794 Harshman, L. G., \& Zera, A. J. (2007). The cost of reproduction: The devil in the details. Trends in Ecology \& Evolution, 22(2), 80-86. https://doi.org/10.1016/j.tree.2006.10.008 Higham, J. P., Brent, L. J. N., Dubuc, C., Accamando, A. K., Engelhardt, A., Gerald, M. S., Heistermann, M., \& Stevens, M. (2010). Color signal information content and the eye of the beholder: A case study in the rhesus macaque. Behavioral Ecology, 21(4), 739-746. https://doi.org/10.1093/beheco/arq047

Higham, J. P., Hughes, K. D., Brent, L. J. N., Dubuc, C., Engelhardt, A., Heistermann, M., Maestriperi, D., Santos, L. R., \& Stevens, M. (2011). Familiarity affects the assessment of female facial signals of fertility by free-ranging male rhesus macaques. Proceedings of the Royal Society of London B: Biological Sciences, 278(1723), 3452-3458. https://doi.org/10.1098/rspb.2011.0052

Higham, J. P., \& Maestriperi, D. (2014). The costs of reproductive success in male rhesus macaques (Macaca mulatta) on Cayo Santiago. International Journal of Primatology, 35, 661-676.

Hodges, J. K., \& Heistermann, M. (2011). Field endocrinology: Monitoring hormonal changes in free-ranging primates. In Field and laboratory methods in primatology: A practical guide (Cambridge University Press). Joanna M. Setchell and Deborah J. Curtis. Hopper, L. M., Gulli, R. A., Howard, L. H., Kano, F., Krupenye, C., Ryan, A. M., \& Paukner, A. (2020). The application of noninvasive, restraint-free eye-tracking methods for use with nonhuman primates. Behavior Research Methods. https://doi.org/10.3758/s13428-020-014656

Huffman, M. A. (1991). Mate selection and partner preferences in female Japanese macaques. In The monkeys of Arashiyama: Thirty-five years of research in Japan and the West (SUNY Press, pp. 101-122). Linda Marie Fedigan, Pamela J. Asquith.

https://books.google.co.jp/books?hl=en\&lr=\&id=9zwroOXx4WoC\&oi=fnd\&pg=PA101\&dq $=$ Mate + selection + and + partner + preferences + in + female + Japanese + macaques $\&$ ots $=q 0$ NNgpyu 75\&sig=fGk8-GdQjXM45uCTNvUtXycMmgQ Huffman, M. A. (1992). Influences of female partner preference on potential reproductive outcome in Japanese macaques. Folia Primatologica, 59(2), 77-88.

Ims, R. A. (1990). The ecology and evolution of reproductive synchrony. Trends in Ecology \& Evolution, 5(5), 135-140. https://doi.org/10.1016/0169-5347(90)90218-3 Johnstone, R. A., Reynolds, J. D., \& Deutsch, J. C. (1996). Mutual mate choice and sex differences in choosiness. Evolution, 50(4), 1382-1391. https://doi.org/10.2307/2410876 Kokko, H., Brooks, R., Jennions, M. D., \& Morley, J. (2003). The evolution of mate choice and mating biases. Proceedings of the Royal Society of London B: Biological Sciences, 270(1515), 653-664. https://doi.org/10.1098/rspb.2002.2235

Kvarnemo, C., \& Ahnesjo, I. (1996). The dynamics of operational sex ratios and competition for mates. Trends in Ecology \& Evolution, 11(10), 404-408. https://doi.org/10.1016/01695347(96)10056-2

Lande, R. (1980). Sexual dimorphism, sexual selection, and adaptation in polygenic characters. Evolution, 34(2), 292-305. https://doi.org/10.2307/2407393

LaPlante, L. H., \& Delaney, S. (2020). Male mate choice for a female ornament in a monogamous cichlid fish, Mikrogeophagus ramirezi. Journal of Fish Biology, 96(3), 663668. https://doi.org/10.1111/jfb.14257

LeBas, N. R., Hockham, L. R., \& Ritchie, M. G. (2003). Nonlinear and correlational sexual selection on 'honest' female ornamentation. Proceedings of the Royal Society of London B: Biological Sciences, 270(1529), 2159-2165. https://doi.org/10.1098/rspb.2003.2482 LeBas, N. R., \& Marshall, N. J. (2000). The role of colour in signalling and male choice in the 
agamid lizard Ctenophorus ornatus. Proceedings of the Royal Society of London. Series B: Biological Sciences, 267(1442), 445-452. https://doi.org/10.1098/rspb.2000.1020 Lukas, D., \& Clutton-Brock, T. (2014). Costs of mating competition limit male lifetime breeding success in polygynous mammals. Proceedings of the Royal Society of London B: Biological Sciences, 281(1786), 20140418. https://doi.org/10.1098/rspb.2014.0418 Mahr, K., Griggio, M., Granatiero, M., \& Hoi, H. (2012). Female attractiveness affects paternal investment: Experimental evidence for male differential allocation in blue tits. Frontiers in Zoology, 9(1), 14. https://doi.org/10.1186/1742-9994-9-14

Marty, J. S., Higham, J. P., Gadsby, E. L., \& Ross, C. (2009). Dominance, coloration, and social and sexual behavior in male drills Mandrillus leucophaeus. International Journal of Primatology, 30(6), 807-823. https://doi.org/10.1007/s10764-009-9382-x

661

662 Matsubara, M. (2003). Costs of Mate Guarding and Opportunistic Mating Among Wild Male Japanese Macaques. International Journal of Primatology, 24(5), 1057-1075.

663 https://doi.org/10.1023/A:1026228312706

664 Møller, A. P., Christe, P., \& Lux, E. (1999). Parasitism, host immune function, and sexual selection. The Quarterly Review of Biology, 74(1), 3-20.

665

666

667 Montoya, B., Flores, C., \& Torres, R. (2018). Repeatability of a dynamic sexual trait: Skin color variation in the Brown Booby (Sula leucogaster). The Auk, 135(3), 622-636. https://doi.org/10.1642/AUK-17-150.1

Muller, M. N., Thompson, \& Wrangham, R. W. (2006). Male chimpanzees prefer mating with old females. Current Biology: CB, 16(22), 2234-2238. https://doi.org/10.1016/j.cub.2006.09.042 Nakagawa, S., \& Schielzeth, H. (2013). A general and simple method for obtaining R2 from generalized linear mixed-effects models. Methods in Ecology and Evolution, 4(2), 133-142. https://doi.org/10.1111/j.2041-210x.2012.00261.x Ogden, H. J. P., de Boer, R. A., Devigili, A., Reuland, C., Kahrl, A. F., \& Fitzpatrick, J. L. (2020). Male mate choice for large gravid spots in a livebearing fish. Behavioral Ecology, 31(1), 63-72. https://doi.org/10.1093/beheco/arz156

O’Neill, A. C., Fedigan, L. M., \& Ziegler, T. E. (2004). Relationship between ovarian cycle phase and sexual behavior in female Japanese macaques (Macaca fuscata). American Journal of Physical Anthropology, 125(4), 352-362. https://doi.org/10.1002/ajpa.20024

680 Peters, A., Kurvers, R. H. J. M., Roberts, M. L., \& Delhey, K. (2011). No evidence for 681 general condition-dependence of structural plumage colour in blue tits: An experiment. Journal of Evolutionary Biology, 24(5), 976-987. https://doi.org/10.1111/j.1420-

684 9101.2011.02229.x Is male rhesus macaque facial coloration under intrasexual selection? Behavioral Ecology, 28(6), 1472-1481. https://doi.org/10.1093/beheco/arx110 Pflüger, L. S., Valuch, C., Gutleb, D. R., Ansorge, U., \& Wallner, B. (2014). Colour and contrast of female faces: Attraction of attention and its dependence on male hormone status in Macaca fuscata. Animal Behaviour, 94, 61-71. https://doi.org/10.1016/j.anbehav.2014.05.022 Pilastro, A., Griggio, M., \& Matessi, G. (2003). Male rock sparrows adjust their breeding strategy according to female ornamentation: Parental or mating investment? Animal Behaviour, 66(2), 265-271.

Pisanski, K., Oleszkiewicz, A., Plachetka, J., Gmiterek, M., \& Reby, D. (2018). Voice pitch modulation in human mate choice. Proceedings of the Royal Society B: Biological Sciences, 285(1893), 20181634. https://doi.org/10.1098/rspb.2018.1634

Rigaill, L., Higham, J. P., Winters, S., \& Garcia, C. (2019). The redder the better? Information content of red skin coloration in female Japanese macaques. Behavioral Ecology and Sociobiology, 73(8), 103. https://doi.org/10.1007/s00265-019-2712-x 
Rigaill, L., MacIntosh, A. J. J., Higham, J. P., Winters, S., Shimizu, K., Mouri, K., Furuichi, T., \& Garcia, C. (2015). Multimodal advertisement of pregnancy in free-ranging female Japanese macaques (Macaca fuscata). PLoS ONE, 10(8), e0135127. https://doi.org/10.1371/journal.pone.0135127 Rigaill, L., MacIntosh, A. J. J., Higham, J. P., Winters, S., Shimizu, K., Mouri, K., Suzumura, T., Furuichi, T., \& Garcia, C. (2017). Testing for links between face color and age, dominance status, parity, weight, and intestinal nematode infection in a sample of female Japanese macaques. Primates, 58(1), 83-91. https://doi.org/10.1007/s10329-016-0575-6 Roberts, J. A., \& Uetz, G. W. (2005). Information content of female chemical signals in the wolf spider, Schizocosa ocreata: Male discrimination of reproductive state and receptivity. Animal Behaviour, 70(1), 217-223. https://doi.org/10.1016/j.anbehav.2004.09.026 Setchell, J. M., \& Dixson, A. F. (2001). Changes in the secondary sexual adornments of male mandrills (Mandrillus sphinx) are associated with gain and loss of alpha status. Hormones and Behavior, 39(3), 177-184. https://doi.org/10.1006/hbeh.2000.1628 Setchell, J. M., Vaglio, S., Moggi-Cecchi, J., Boscaro, F., Calamai, L., \& Knapp, L. A. (2010). Chemical composition of scent-gland secretions in an old world monkey (Mandrillus sphinx): Influence of sex, male status, and individual identity. Chemical Senses, 35(3), 205220. https://doi.org/10.1093/chemse/bjp105

Setchell, J. M., \& Wickings, J. E. (2006). Mate choice in male mandrills (Mandrillus sphinx). Ethology, 112(1), 91-99. https://doi.org/10.1111/j.1439-0310.2006.01128.x Soltis, J., Mitsunaga, F., Shimizu, K., Nozaki, M., Yanagihara, Y., Domingo-Roura, X., \& Takenaka, O. (1997). Sexual selection in Japanese macaques II: Female mate choice and male-male competition. Animal Behaviour, 54(3), 737-746.

https://doi.org/10.1006/anbe.1997.0568

Soudry, O., Kaira, H., Parsa, S., \& Mendelson, T. (2020). Male rainbow darters (Etheostoma caeruleum) prefer larger conspecific females. Behavioural Processes, 170, 104013. https://doi.org/10.1016/j.beproc.2019.104013

Stevens, M., Stoddard, M. C., \& Higham, J. P. (2009). Studying primate color: Towards visual system-dependent methods. International Journal of Primatology, 30(6), 893-917. https://doi.org/10.1007/s10764-009-9356-z

Symonds, M. R. E., \& Moussalli, A. (2011). A brief guide to model selection, multimodel inference and model averaging in behavioural ecology using Akaike's information criterion. Behavioral Ecology and Sociobiology, 65(1), 13-21. https://doi.org/10.1007/s00265-0101037-6 Thompson, M. E. (2018). Reproductive seasonality. In The International Encyclopedia of Biological Anthropology (pp. 1-2). American Cancer Society. https://doi.org/10.1002/9781118584538.ieba0425

Thompson, M. E., \& Georgiev, A. V. (2014). The high price of success: Costs of mating effort in male primates. International Journal of Primatology, 35(3-4), 609-627. https://doi.org/10.1007/s10764-014-9790-4

Thomsen, R., Soltis, J., Matsubara, M., Matsubayashi, K., Onuma, M., \& Takenaka, O. (2006). How costly are ejaculates for Japanese macaques? Primates; Journal of Primatology, 47(3), 272-274. https://doi.org/10.1007/s10329-005-0171-7

Thrall, P. H., Antonovics, J., \& Dobson, A. P. (2000). Sexually transmitted diseases in polygynous mating systems: Prevalence and impact on reproductive success. Proceedings of the Royal Society B: Biological Sciences, 267(1452), 1555-1563.

Torres, R., \& Velando, A. (2005). Male preference for female foot colour in the socially monogamous blue-footed booby, Sula nebouxii. Animal Behaviour, 69(1), 59-65. https://doi.org/10.1016/j.anbehav.2004.03.008

748 Townsend, S. W., Deschner, T., \& Zuberbühler, K. (2011). Copulation calls in female 
chimpanzees (Pan troglodytes schweinfurthii) convey identity but do not accurately reflect fertility. International Journal of Primatology, 32(4), 914-923.

751 https://doi.org/10.1007/s10764-011-9510-2

752 Trivers, R. L. (1972). Parental investment and sexual selection. In Sexual Selection and the

753 Descent of Man, 1871-1971. B. Campbell.

754 Wada, S., Arashiro, Y., Takeshita, F., \& Shibata, Y. (2011). Male mate choice in hermit crabs: Prudence by inferior males and simple preference by superior males. Behavioral Ecology, 22(1), 114-119. https://doi.org/10.1093/beheco/arq183 Waitt, C., Little, A. C., Wolfensohn, S., Honess, P., Brown, A. P., Buchanan-Smith, H. M., \& Perrett, D. I. (2003). Evidence from rhesus macaques suggests that male coloration plays a

759 role in female primate mate choice. Proceedings of the Royal Society B: Biological Sciences,

760 270(Suppl 2), S144-S146. https://doi.org/10.1098/rsbl.2003.0065

761 Waner, S., Motro, U., Lubin, Y., \& Harari, A. R. (2018). Male mate choice in a sexually cannibalistic widow spider. Animal Behaviour, 137, 189-196.

763 https://doi.org/10.1016/j.anbehav.2018.01.016

764 Weiss, S. L. (2002). Reproductive signals of female lizards: Pattern of trait expression and male response. Ethology, 108(9), 793-813. https://doi.org/10.1046/j.1439-0310.2002.00819.x Weiss, S. L. (2016). Ornamentation, age, and survival of female striped plateau lizards, Sceloporus virgatus. The Science of Nature, 103(3-4), 16. Wright, D. S., Pierotti, M. E. R., Rundle, H. D., \& McKinnon, J. S. (2015). Conspicuous Female Ornamentation and Tests of Male Mate Preference in Threespine Sticklebacks (Gasterosteus aculeatus). PLOS ONE, 10(3), e0120723.

771 https://doi.org/10.1371/journal.pone.0120723

772 Yorzinski, J. L., Patricelli, G. L., Babcock, J. S., Pearson, J. M., \& Platt, M. L. (2013).

773 Through their eyes: Selective attention in peahens during courtship. The Journal of

774 Experimental Biology, 216(16), 3035-3046. https://doi.org/10.1242/jeb.087338 

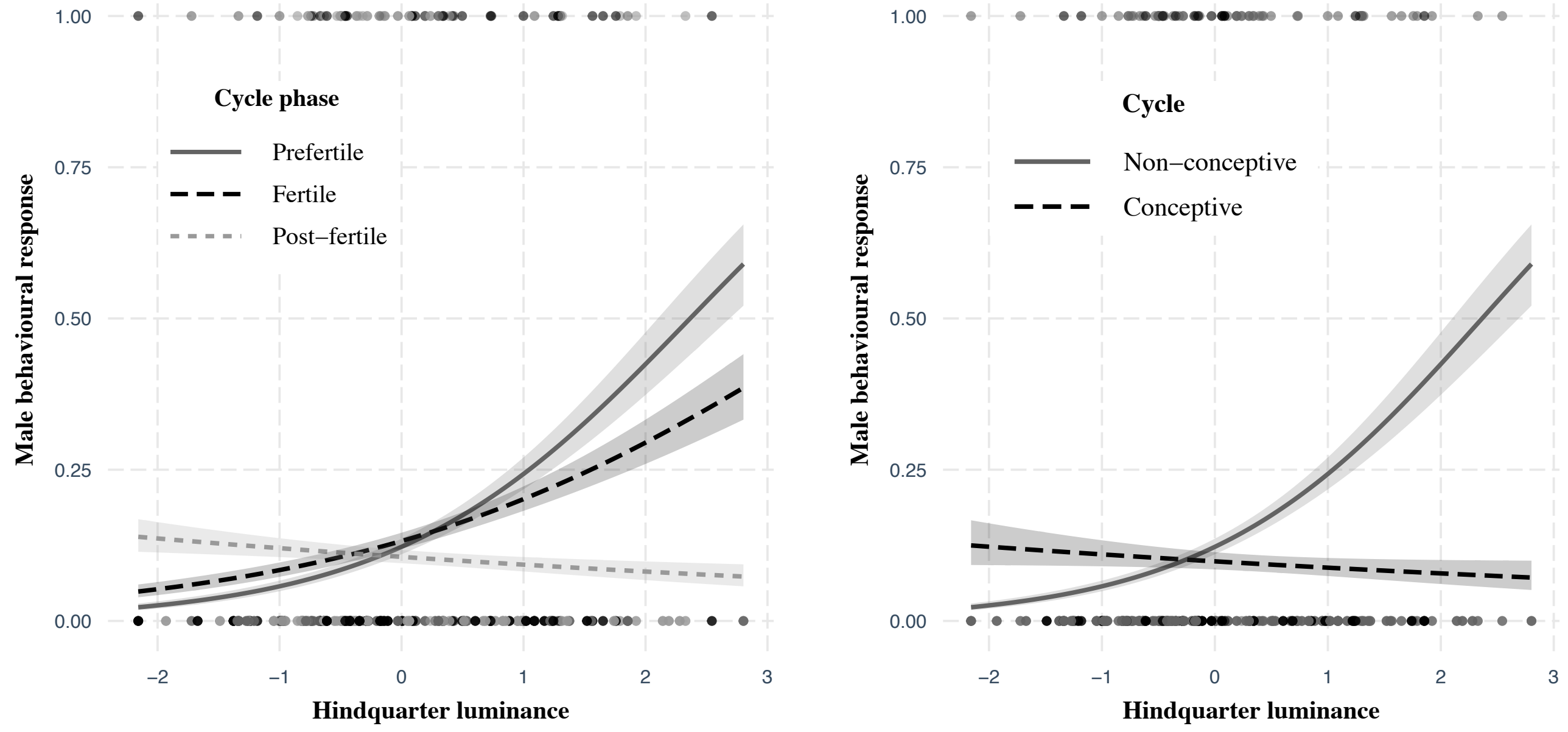